Military Technical College

Kobry El-Kobbah,

Cairo, Egypt

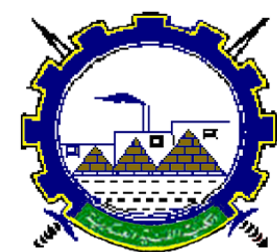

I.C.E.E.2016 $8^{\text {th }}$ International Conference

on

Chemical \& Environmental

Engineering

$19-21$ April 2016

EEA-2

\title{
Alum Sludge: Conditioning, Dewatering and Drying Using a Pilot ScaleDemonstrationSolar Dryer
}

\author{
A. M. Tayeb ${ }^{1}$, Maha A. Tony ${ }^{2 *}$
}

\begin{abstract}
A large quantity of sludge is generated each year from water treatment plants in Egypt. Disposing such sludge to the nearest watercourse is the common practice in Egypt, which accumulatively rise the aluminum concentrations in water and consequently in human bodies. Sludge reduction and dewatering is an important aspect of water treatment. This is causes a challenege to the Egyptian government program, where the reduction in volume of wastes to lead to significant transport and handling cost savings. In this investigation, water treatment sludges was collected from the water treatment plant from Kedwan Station water treatment plant, in the South of Egypt, Elminia City. In this study, a novel combination of chemical and physical conditioning, with the application of solar drying were examined to explore their integrated influence on the dewatering of alum sludge. Moreover, evaporative solar dryer system has been installed on the sun-shine to convert alum sludge into a drier, through solar radiation exposure resulting in decreased moisture concentration. Such conditioners are, Fenton's reagent, gypsum, $\mathrm{FeCl}_{3}$, anionic and cationic polymers and hydrogen peroxide. A comparative investigation is monitored and a combination between conditioners are applied to get the optimum dewatering facility. The average sludge moisture content decreased from $94 \%$ to $6 \%$ within one day in summer, resulting to a dry product. Solar sludge drying method was proved to be efficient for regions which receive high annual solar radiation such as Egypt.
\end{abstract}

Keywords: Water works plants, Solar, Drying, Dewatering, Alum Sludge

\footnotetext{
${ }^{1}$ Chemical Engineering Department, Faculty of Engineering, EL-Minia University,

${ }^{2}$ Basic Engineering Science Department, Faculty of Engineering, Minoufiya University

*Corresponding Author: Tel: +2048-2221549, Fax:+20482235695, Email: maha_tony1@yahoo.com
} 
Military Technical College

Kobry El-Kobbah,

Cairo, Egypt

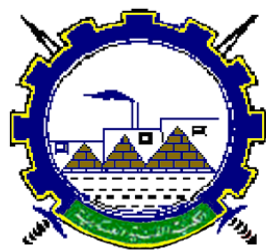

I.C.E.E.2016 $8^{\text {th }}$ International Conference

on

Chemical \& Environmental

Engineering

$19-21$ April 2016

\section{Introduction}

Aluminium sulphate is probably the most widely used coagulant in the treatment of raw water for the production of drinking water. The floc among the resultant aluminium-based water treatment sludge, forms a three-dimensional network and is a two-phase mixture of solids and water. The water content of the sludge is generally in the level between $99 \%$ (before thickening) and 95\% (after thickening).Such sludges are often regarded as 'difficult to dewater' [1]. The conditioning of the sludge leads to the improvement of its dewaterability in subsequent mechanical dewatering operation. During the conditioning process small and amorphous gel like particles in the sludge are transformed into larger and stronger aggregates, thereby increasing the rate of water release and solid separation [2].

The protection of the environment and natural resources is increasingly becoming a very important goal especially through environmentally sustainable waste management programs. It is necessary to follow, on the part of waste managers, a sustainable approach to waste management and to integrate strategies that will produce the best practicable option. However, it may be a very challenging task since it involves taking into account economic, technical, and environmental issues [3]. Increasing amounts of such waste, both solid and liquid, are being generated as a result of the rapid rate of urbanisation. It is estimated 60 million tones of solid waste are generated every year in Egypt (Fig. 1). This in turn presents greater difficulties for disposal. For centuries, agriculture has occupied a pivotal position in the operation of the Egyptian economy and remains one of the largest sectors of the Egyptian economy [4]. The protection of the environment and natural resources is increasingly becoming very important through environmentally sustainable waste management programs. Thus, alternative managing methods is needed to divert waste from landfill or incineration.

Chemical conditioning of sludge is a worldwide dominant method in practice. Notably, polymers among many other chemicals, such as ferric salts and lime etc. are most widely employed conditioners [1,5]. However, in recent years, considerable studies have been carried out to explore Fenton's reagent as an alternative chemical conditioner of sludge. For example, $\mathrm{Lu}$ et al., [6] examined four ratios of $\mathrm{Fe}^{2+} / \mathrm{H}_{2} \mathrm{O}_{2}$ to investigate the effect of $\mathrm{Fe}^{2+}$ concentration on the reduction of the specific resistance to filtration (SRF) of an activated sludge. Buyukkamaci [7] studied the effect of various concentrations of $\mathrm{Fe}^{2+}$ and $\mathrm{H}_{2} \mathrm{O}_{2}$ on SRF and CST (capillary suction time) of biological sludge and obtained the minimum CST at dosage of $5 \mathrm{~g} \mathrm{Fe}^{2+} / \mathrm{L}$ and $6 \mathrm{~g} / \mathrm{L}$ of $\mathrm{H}_{2} \mathrm{O}_{2}$.

For long decades, traditional sun drying methods is commonly used for drying different products drying has been a way of preserving and saving foods for storing during long periods. It is a cheap method of drying produce as the sunlight is free and low operating costs [8]. It is used for drying different products such as medicinal herbs, preserved food, herbs, Cocoa Beans and spices 9, 10] although this method is very cheap and practice, however the 
Military Technical College

Kobry El-Kobbah,

Cairo, Egypt

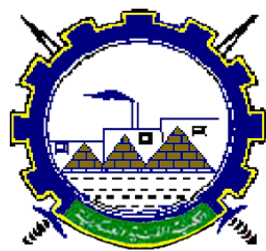

I.C.E.E.2016 $8^{\text {th }}$ International Conference

on

Chemical \& Environmental

Engineering

$19-21$ April 2016

dry products are of poor quality due to contamination and also slow drying time. However, according to the literature, this process is not applied so far in the solid waste management processes. Although, there are some disadvantages too from applying the sun drying procedure. The temperature of sunlight cannot be controlled. The weather is not always sunny, and sometimes the drying process can take several days.

Egypt has endowed with a high solar intensity; the annual global radiation is between 7 and $9 \mathrm{GJ} / \mathrm{m}^{2}$. In Upper Egypt, the winters are mild and summers are hot in the daytime and warm at night, with maximum temperatures from $34^{\circ} \mathrm{C}$ to $40.8^{\circ} \mathrm{C}$. Sunshine falls on the ground surface well over $90 \%$ of the possible time $[11,12]$.

Over the last years, solar sludge drying has acquired significant interest. Sludge drying is, obviously, dewatering the sludge completely after dewatering or sometimes in place of dewatering. This usually involves sludge drying beds in a solar sludge drying process. In fact, sludge drying is largely a process used in sewage treatment. Lower operating costs, along with the inherit safety and environmental friendliness of solar drying made the sludge dryer a clear choice for sludge dewatering. The heat needed for the drying process currently comes solely from the sun.

The aim of this work is to present a detailed description of the benefits of using solar drying. In this study, different solar-chemical conditioners such as Fenton's reagent, polymer and $\mathrm{FeCl}_{3}$ or solar-physical conditioner such as gypsum augmented with solar energy were employed to condition alum based drinking water treatment sludge collected from a local water treatment plant. Emphases are placed on: (1) the effectiveness of different solar chemical conditioners reaction in improving sludge dewaterability, which was evaluated by Moisture content (M.C.), (2) effect of physical conditioner, (2) effect of dual physic-chemical solar conditioners, and (3) comparison between different conditioners to achieve the maximum (M.C.) reduction of the sludge.

\section{Materials and methods of the experimental work}

\subsection{Description of the experimental site}

The experimental site was located at the Chemical Engineering Department of Minia University, in El-minia City, $250 \mathrm{~km}$ south of Cairo city, Egypt. The latitude, longitude and altitude of the location are latitude $28^{\circ}$ and $28^{\circ} 40^{\prime} \mathrm{N}$ and longitudes $31^{\circ} 30^{\prime} \mathrm{E}$ and $130 \mathrm{~m}$ above sea level, respectively. The region experiences usually mild, sunny and dry seasons [13, 14].

\subsection{Design futures and description of the solar drier}

The dryer (Fig. 2) was conceived as low-cost, easy-to-fabricate and easy-to-operate equipment. The solar tunnel drier consists of a flat plate air heating collector, a tunnel drying 
Military Technical College

Kobry El-Kobbah,

Cairo, Egypt

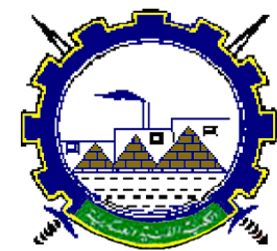

I.C.E.E.2016 $8^{\text {th }}$ International Conference

on

Chemical \& Environmental

Engineering

$19-21$ April 2016

chamber and a small fan to provide the required air flow over the products to be dried. Both the collector and drying units are covered with UV stabilized glass covers. These are connected in series as shown in Fig.2. The whole system is placed horizontally on a raised platform for easy loading and unloading of the products to be dried. The solar collector is basically a top-open, wooden box, $300 \times 100 \mathrm{Cm}^{2}$ made from $4.5 \mathrm{~cm}$ thick plywood with edges height of $15 \mathrm{~cm}$. The box was inclined to keep its top surface, covered with a Plexiglas, at about $28^{\circ} 40^{\prime}$ to the horizontal. Black paint is used as an absorber in the collector. Insulation is provided on the back sides of the collector and the drying unit to reduce the heat losses from the drier. The drying chamber is constructed of Plexiglas and fitted with a 2 trays which are manufactured from wire sieves stainless steel. The chamber is $100 \times 95 \times 150 \mathrm{Cm}^{3}$ and a thickness of $0.25 \mathrm{~cm}$. The air at required flow rate is provided by electric operated fan driven by an electric motor.

\subsection{Experimental materials}

The experimental alum sludge was collected from the underflow of the sedimentation tank of a local waterworks in south of Minia City in the South of Egypt, Kedwan station water works plant, which treats reservoir water using aluminium sulphate as a primary coagulant. Principle properties of the alum sludge which measured and monitored in the laboratory are given in Table 1.

Table 1 Properties of alum sludge used in this study

\begin{tabular}{lll}
\hline Parameters & Unit & Value \\
\hline Suspend solid (SS) & $\mathrm{mg} / \mathrm{l}$ & 2,364 \\
$\mathrm{pH}$ & & 8.5 \\
SRF & $\mathrm{m} / \mathrm{kg}$ & $2.24 \times 10^{13}$ \\
Turbidity & $\mathrm{NTU}$ & 274 \\
(supernatant) & & \\
Moisture Content & $\%$ & 97 \\
\hline
\end{tabular}

Ferrous oxalate and hydrogen peroxide are used as the source of Fenton's reagent. Sulfuric acid and $\mathrm{NaOH}$ are used for $\mathrm{pH}$ adjustment. All of those chemicals are supplied by SigmaAldrich and used without further purifications. However, Magnafloc polymer LT-25 and FO4140 PWG are used as the source of polyelectrolyete which are supplied by CIBA Speciality Chemicals Ltd., UK and SNF SAC ZACde Milieux, France, respectivily.

\subsection{Experimental Methods and Analytical Determinations}

The experimental campaign included the monitoring of the sludge drying process during summer period, in order to obtain data about process efficiency. For the drying tests, $5 \mathrm{~g}$ of the material to be dried were placed on the trays of the drying chambers and used for each 
Military Technical College

Kobry El-Kobbah,

Cairo, Egypt

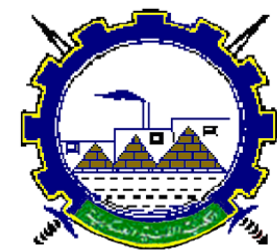

I.C.E.E.2016 $8^{\text {th }}$ International Conference

on

Chemical \& Environmental

Engineering

$19-21$ April 2016

experimental run. The tests were carried out during the period of May 2013 to October 2014 and from April 2014 to August 2015. The experiments were started at 9.00 am and continued till $8.00 \mathrm{pm}$. Solar radiation was measured by solarimeter (Epply black-and-white solarimeter, model 8-48). Hot wire anemometers (Airflow, model TA5, accuracy $72 \%$ ) were employed to monitor the air speed in the collectors and air ducts. Thermocouples were used to measure air temperatures in the collectors, air ducts and drying samples. During drying of food residuals samples, the solar radiation in the upper of Egypt is varied from 87 to $1025 \mathrm{~W} / \mathrm{m}^{2}$, while the ambient temperature is varied from 27 to $40^{\circ} \mathrm{C}$. The process was repeated until the desired moisture content was reached. The moisture content during drying was estimated from the weight of the product samples and the estimated dried solid mass of the sample. However, it is assumed that there is no mass loss from the air flow because it is not high enough to loss the solid material and the temperature is not so much high to decompose it. At the end of the drying process, the exact dry solid mass of the product samples was determined by using oven. The product sample was taken from the dryer and weighed at 15-min intervals. Electrical energy was used only to run the electric motor to operate fan to provide the desired airflow (air velocity of $200 \mathrm{~m} / \mathrm{s}$ in the drying) in this tunnel solar dryer.

\section{Results and discussions}

\subsection{Effect of reaction time and sun/solar drying}

Raw alum sludge is put in the solar dryer and left to get dewatering. Different samples are taken during the time and the moisture content is monitored. The $\%$ of moisture content is decreased with increasing the reaction time in the solar dryer after the sludge is submitted to the dryer. It is obvious that around the solar noon the maximum drying efficiency is taking place. \% M.C. is reached to around $2.5 \%$ at the end of the day. The economical reaction time is chosen as $3 \mathrm{~h}$.

For the object of comparison, the samples are subjected to the solar dryer in parallel at the same conditions and the same solar intensity. The moisture content is monitored. It is found that the direct sun drying is effective, however, when the moisture content is reached to around $12 \%$ in the direct sun, the moisture content in the solar dryer is reached to $1.0 \%$. This means the solar dryer is more effective than the direct sun drying. In other words, when the solar dryer is more effective than the direct-sun because of the presence of the air flow and heat is conserved inside the dryer [15].

The effect of solar intensity during the reaction time on the moisture content percent is studied. As illustrated in Table 2, high solar intensity is given around the solar noon which is ranged from 980 to $1025 \mathrm{~W} / \mathrm{m}^{2}$, and at that time the M.C. \% is decreased dramatically. Afterwards, the solar intensity is decreased to $310 \mathrm{w} / \mathrm{m}^{2}$ however, the solar dryer is still 
Military Technical College

Kobry El-Kobbah,

Cairo, Egypt

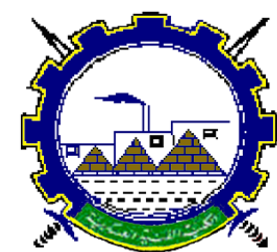

I.C.E.E.2016 $8^{\text {th }}$ International Conference

on

Chemical \& Environmental

Engineering

$19-21$ April 2016

having the heat which able to dry the samples[3]. However, for the samples subjected to the direct sun drying this takes five days to reduce the M.C. to a noticable vales.

Table 2 Effect of solar intensity around the day on the \%M.C. of the sludge in the solar dryer

\begin{tabular}{ccc}
\hline Local time & S.I, W/m & M.C, $\%$ \\
\hline $10: 00$ & 850 & 11.67 \\
$11: 00$ & 980 & 10.61 \\
$12: 00$ & 940 & 10.38 \\
$13: 00$ & 860 & 10.07 \\
$14: 00$ & 690 & 8.09 \\
$15: 00$ & 550 & 4.12 \\
$16: 00$ & 310 & 2.51 \\
\hline
\end{tabular}

\subsection{Effect of solar/chemical dewatering:}

\subsubsection{Effect of $\mathrm{FeCl}_{3}$ addition:}

Traditional chemical conditioner which used in the traditional water works plants in the world is used for the comparison with the new trends. For the object of comparison, different amounts are added and the value is monitored for optimum value. As seen in fiure 3 the value of $80 \mathrm{mg} / \mathrm{L}$ is showed to be the optimum, when the value is more than that value the \% M.C. is decreased, this is because of the settling instead of attacking the sludge for floc making. Simply, Ferric chloride is a flloculant for the sludge, it aggromerate the sludge into flocs and helps in the water release from it [5].

\subsubsection{Fenton's reagent dewatering}

Fenton's reagent is applied and consisting of three operating variables, hydrogen peroxide, Fe-salt with $\mathrm{pH}$ adjustment. Such variables are needed to be optimized.

Factors to control the Fenton reaction process are the amounts of $\mathrm{Fe}^{2+}$ and $\mathrm{H}_{2} \mathrm{O}_{2}$, and $\mathrm{pH}$. Optimizing such amounts plays a key role towards the success of the Fenton process. From our previous work (under publication), the optimum conditions for the drying facility is obtained, i.e. $\mathrm{Fe}^{2+}=40 \mathrm{mg} / \mathrm{L}$, and $\mathrm{H}_{2} \mathrm{O}_{2}=610 \mathrm{mg} / \mathrm{L}$ and $\mathrm{pH}$ was 7 which prevails a reduction in the dewaterability of the sludge reached to $92.7 \%$ solids concentration. Thus, could be 
Military Technical College

Kobry El-Kobbah,

Cairo, Egypt

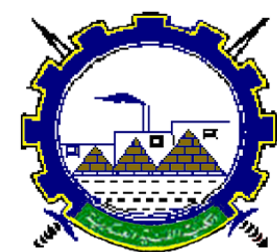

I.C.E.E.2016 $8^{\text {th }}$ International Conference

on

Chemical \& Environmental

Engineering

$19-21$ April 2016

illustrated by the fact that $\mathrm{OH}$ radicals which is produced during the Fenton's reagent process could be maximuzed at the optimum conditions and the $\mathrm{OH}$ radicals attaching the sludge molecules and causes to the water release. This water is evaporized during the solar dryer process [16].

\subsubsection{Effect of polymer dewatering}

For the object of comparison, polymer is used for conditioning in a wide range in water treatment plants around the world. Two types of polymer were added at their optimum values according to the previous work [16]. Cationic polymer is added at $20 \mathrm{mg} / \mathrm{L}$ and anionic polymer is added at $10 \mathrm{mg} / \mathrm{L}$. In addition the flow rate of air flows in the dryer is subjected at $200 \mathrm{~m} / \mathrm{s}$ and the samples are subjected to the solar dryer. The M.C. reduction gets a better dewterability as shown in Fig. 4.

The effectiveness of the conditioning in the case of the cationic polymer is higher than that of the anionic polymer. This is believed to be due to the differences in the nature and the ionic charge of the polymers, which control the coagulation and flocculation [17, 18]. However, we should consider the toxicity of the polymer usage compared to the harmless end products of Fenton's reagent.

\subsubsection{Dewaterability with hydrogen peroxide}

Hydrogen peroxide alone is added as a conditioner for the sludge to enhance the dewatering process. Four hydrogen peroxide samples are added at different concentrations. It is obvious from Fig. 5, the optimum hydrogen peroxide is reached at $100 \mathrm{mg} / \mathrm{L}$ where the M.C $\%$ is reached to $3.2 \%$. This means if hydrogen peroxide is used in the optimum value it agglomerates the sludge particles and enhance the water drying process.

The use of hydrogen peroxide alone only slightly modified the sludge composition and resulted in lower hydration of the sludge cake after filtration, as compared to the nonconditioned sludge. High doses of hydrogen peroxide causes excess in water solution and not enhancing the decrease in water release[16].

\subsection{Physical skelton builder in sludge dewatering:}

First, some sets of experiments were done in order to enhance the performance. The intention was to prepare a gypsum slurry with water before addition. However, it was found that, the performance decreased as the amount of water increased. From that it is concluded to add gypsum directly to the sludge. 
Military Technical College

Kobry El-Kobbah,

Cairo, Egypt

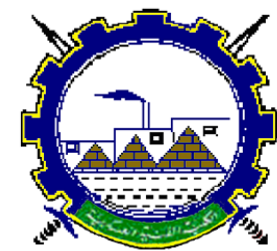

I.C.E.E.2016 $8^{\text {th }}$ International Conference

on

Chemical \& Environmental

Engineering

$19-21$ April 2016

A Skelton builder, gypsum is used to enhance the floc making and the water release is increased in order to increase the sludge drying. Different doses are added and the M.C. is measured. As shown in Fig.6, the gypsum doses are added in the following doses, 5, 10, 20, $30 \mathrm{mg} / \mathrm{L}$. The optimum dose as clear from the figure is $5 \mathrm{mg} / \mathrm{L}$ for the operation of the floc making, when the value is more than that the gypsum is in release instead aggregating the sludge particles.

Sludge filterability was improved with the addition of gypsum. The addition of the gypsum enhance the dewatering extent by further decreasing equilibrium cake moisture content. The purpose of the skeleton builder is to form a permeable and rigid lattice structure that can remain porous under high pressure. By examining the polymer residual in the bulk solution and comparing data between the cases of gypsum and glass-microsphere (as a non-shrinking skeletal material) it was evident that the gypsum possesses a polymer demand indicating an interaction between them $[5,19]$.

\subsection{Effect of dual physico-chemical dewatering:}

For the object of more enhancing the dewatering and drying process, alum sludge is subjected for both gypsum as a skelton builder besides the polymer for increasing the floc particles. Both are for increasing the water release and then more water are solar dried. As previously shown anionic polymer is better than the cationic one, thus the anionic optimum one is used after the optimum $(5 \mathrm{mg} / \mathrm{L})$ of gypsum is added, the chemicals are added and stirred then the sludge is subjected to the solar dryer. The values of this process are illustrated in Fig. 7 a. It is obvious from the Fig. 7 a that $5 \mathrm{mg} / \mathrm{L}$ polymer enhancing the process to reach to $1.2 \%$ M.C.

Moreover, the optimum Fenton reagent values (40 and 610 for Ferric oxalate and hydrogen peroxide) and gypsum $(5 \mathrm{mg} / \mathrm{L})$ is added to the sludge sample before submitting it to the solar dryer.

As shown in Fig. $7 \mathrm{~b}$ at the end of experiment the value of the \%M.C. is reached to $1.9 \%$. This means the combination is helpful for releasing more water which is easily dried. The values are illustrated in Fig. 8. it is clear that the addition of both conditioner and the skelton builder together enhancing the process, thus the water is dried faster [5, 19].

\section{5. comparison between different dewatering/conditioning techniques}

The results in Fig. 8 reveal that the polymer conditioning shows a higher reduction compared to Fenton's reagent. However, the harm of the polymer should be considered. In the other hand, gypsum as a skelton builder and a physical conditioner is compared which gives a better 
Military Technical College

Kobry El-Kobbah,

Cairo, Egypt

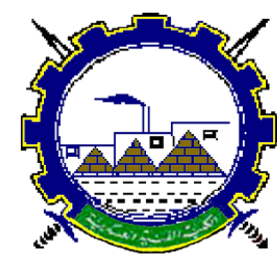

I.C.E.E.2016 $8^{\text {th }}$ International Conference

on

Chemical \& Environmental

Engineering

$19-21$ April 2016

value when it is combined with the Fenton's reagent. The optimum values are compared in each case and the value at the end of the day is monitored.

The evaluated order under a comparable study showed that (polymer+gypsum) $>$ (Fenton's + gypsum) $>$ gypsum $>$ Fenton's $>\mathrm{FeCl}_{3}>$ hydrogen peroxide. These results are in accordance with that conducted by Lu et al., [20] and Krzemieniewski et al., [21] in conditioning digested sludge. Furthermore, $\mathrm{Xu}$ [22] and Wang [23] also found the same trend in treating different wastewater effluents using Fenton and Fenton-like reagents. The mechanism in each process is different, leading to different M.C. reduction rates for the conditioning process.

The mechanism of Fenton reaction in the alum sludge conditioning may be complicated and the exact mechanism may remain unclear in this stage. However, as an attempt to partially try to understand the process, it is reasonable to believe that the $\cdot \mathrm{OH}$ attack of the cells of some particles/materials in the alum sludge, leads to the destruction of the original cells and forming new intermediates. The evidence on this lies in the investigation of the measurement of the molecular size distribution before and after Fenton reagent conditioning in our preliminary work [16]. Thus, both the bound water and the interstitial water were released, and accordingly the filterability and dewaterability of the sludge would increase. Moreover, iron salt in the sludge has its action of coagulating the sludge.

\section{Conclusion}

The results from the present study have demonstrated the effectiveness of the application of physical and chemical dewatering agents. Solar drying showed a positive influence in alum sludge dewatering. Fenton's reagent enhance the dewatering process and the M.C.\% reached to $2.4 \%$. Polymer conditioning reachs the M.C. reduction to slightly more than Fenton's reagent. However, in the combination between the physical and chemical dewatering showed a positive enhancement in the solar dewatering.

\section{References}

[1] Y.Q. Zhao and D. H. Bache, Integrated effects of applied pressure, time, and polymer doses on alum sludge dewatering behaviour, Waste Manag., 22, (2002) 813-819.

[2] W. W. E. Jr and C. J. Santhanam, Sludge treatment, 65, Mercel Dekker, INC., USA, 1981, p. 65.

[3] P., Costi, R., Minciardi, M., Robba, M., Rovatti, and R., Sacile, An environmentally sustainable decision model for urban solid waste management.Waste Management 24 (2004) 277-295. 
Military Technical College

Kobry El-Kobbah,

Cairo, Egypt

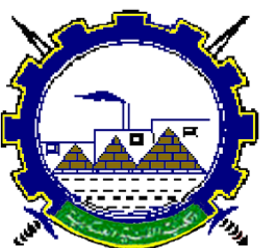

I.C.E.E.2016 $8^{\text {th }}$ International Conference

on

Chemical \& Environmental

Engineering

$19-21$ April 2016

[4] World Bank (1992). World Development Report. Washington D.C.: The World Bank. (Source: national solid waste management programme, January 2015)

[5] Y. Q. Zhao, Involvement of Gypsum $\left(\mathrm{CaSO}_{4} \cdot 2 \mathrm{H}_{2} \mathrm{O}\right)$ in Water Treatment Sludge Dewatering: A Potential Benefit in Disposal and Reuse, Sep. Sci. Technol., 41 (2006) 2785-2794.

[6] M. C. Lu, C.J. Lin, C. H. Liao, R. Y. Huang and W. P. Ting, Dewatering of activated sludge by Fenton's reagent, Advanced Environ. Res., 7 (2003) 667- 670.

[7] N. Buyukkamaci, Biological sludge conditioning by Fenton's reagent, Process Biochem., 39 (2004) 1503-1506.

[8] D. R. Pangavhane; and R. L. Sawhney, Review of research and development work on solar dryers for grape drying, Energy Conv. Manag. 43(2002), 45-61.

[9] Jose K.P., C.M. Joy, Postharvest processing of spices in relation to export quality, Everyman's Sci., 4 (2004) 230.

[10] A.O. Fagunwa, O. A. Koya, and M.O. Faborode, Development of an Intermittent Solar Dryer for Cocoa Beans, Agri. En. Intern., 1292. Vol. XI. July, 2009.

[11] G.E., Ahmad, Photovoltaic-powered rural zone family house in Egypt, Renewable Energy 26 (2002) 379-390

[12] El-Mashad, Wilko H.M., van Loon1, K.P., Zeeman, G., Model of Solar Energy Utilisation in the Anaerobic Digestion of Cattle Manure. Biosyst. Eng., 84 (2003) 231238.

[13] S. Abdel Twab, A Geotechnical Evaluation of Minia-Maghagha Area, Upper Egypt, KA If : Eartl: Sci. mi., 1414 (1994) 7143-157.

[14] H. M., Aly and R.,J. Giardino, Andrew G. Klein, Suitability Assessment for New Minia City, Egypt: A GIS Approach to Engineering Geology, Eviron. Eng. Geosci., 11(2005) 259-269.

[15] N., Rouxa, D., Junga, Pannejonb and J., Cyrille Lemoine, Modelling of the solar sludge drying process Solia ${ }^{\mathrm{TM}}$, 20th European Symposium on Computer Aided Process Engineering - ESCAPE20 S. Pierucci and G. Buzzi Ferraris (Editors) .

[16] M.A., Tony, Y.Q., Zhao, J.F., Fu Ind A.M., Tayeb, Conditioning of aluminium-based water treatment sludge with Fenton's reagent: effectiveness and optimising study to improve dewaterability. Chemosphere 72 (2008) 673-677.

[17] C. C., Wu,C., Huang and D.J., Lee Effects of polymer dosage on alum sludge dewatering characteristics and physical properties. Colloids Surf, A, 122 (1994) 89-96.

[18] Y Q, Zhao and D. H., Bache, Polymer impact on filter blinding during alum sludge filtration, Water Res., 36 (2002) 3691-3698.

[19] Y., Qi, B., Khagendra, A., Thapa, and F.A., Hoadley, Application of filtration aids for improving sludge dewatering properties -A review, Chem. Eng. J. , 171 (2011) 373384. 
Military Technical College Kobry El-Kobbah, Cairo, Egypt

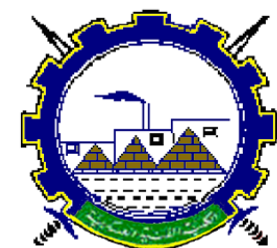

I.C.E.E.2016 $8^{\text {th }}$ International Conference

on

Chemical \& Environmental

Engineering

$19-21$ April 2016

[20] M.C.,Lu, C.J., Lin, C.H., Liao, and W.P., Ting, Huang, R.Y., Influence of pH on the dewatering of activated sludge by Fenton's reagent. Water Sci. Technol., 44(2001), 327332.

[21] M., Krzemieniewski, and M., Debowski, Janczukowicz, P.W.J. Effect of sludge conditioning by chemical methods with magnetic field application, Pol. J. Environ. Stud., 12(2003), 595-605.

[22] Xu, Y. , Comparative studies of the Fe3+/2+-UV, H2O2-UV, TiO2-UV/vis systems for the decolrization of a textile dye X-3B in water. Chemosphere, 43(2001) 1103-1107.

[23] Wang, S.A. , Comparative study of Fenton and Fenton-like reaction kinetics in decolourisation of wastewater, Dyes Pigm., 76 (2008) 714-720.

\section{Figure Captions}

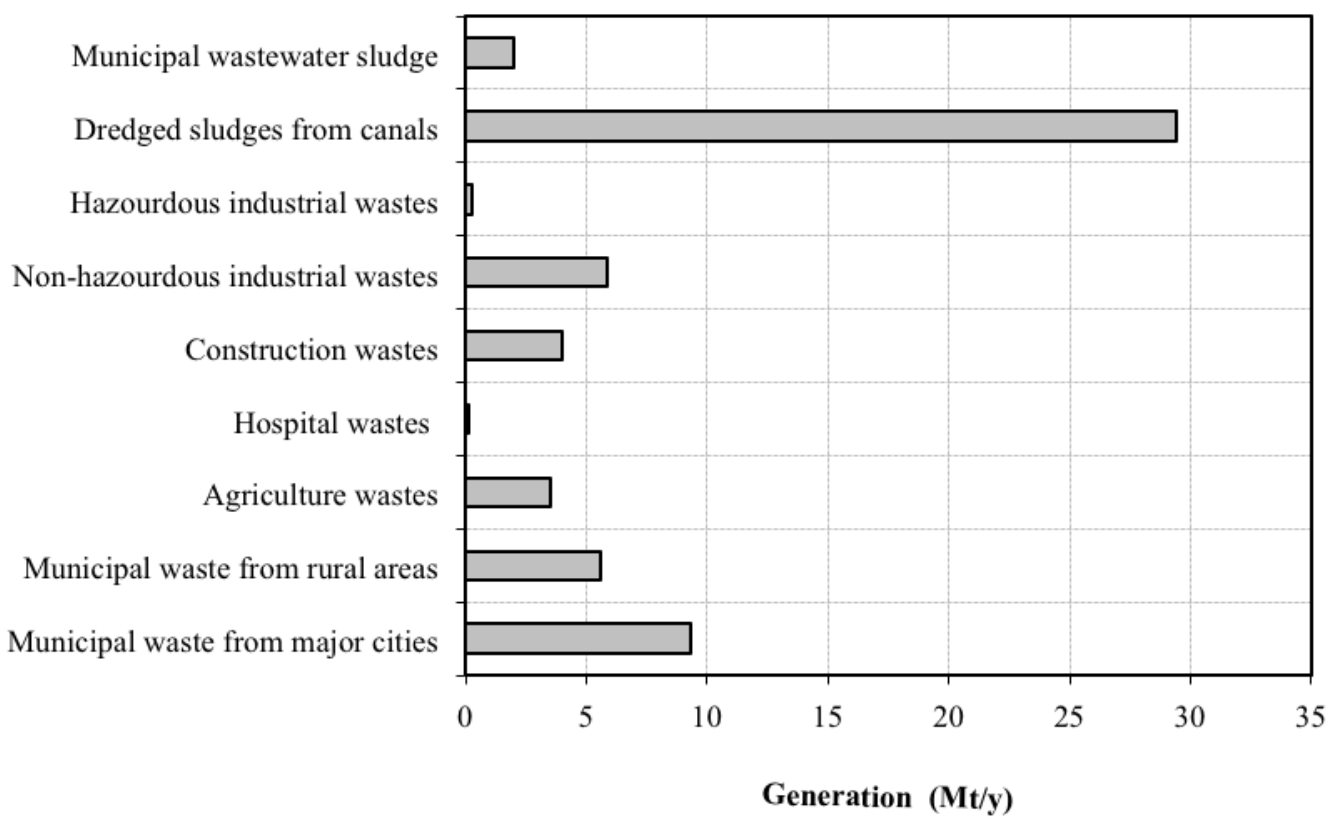

Fig. 1. Distribution of solid waste in Egypt 
Military Technical College Kobry El-Kobbah, Cairo, Egypt

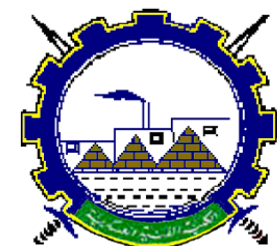

I.C.E.E.2016 $8^{\text {th }}$ International Conference

on

Chemical \& Environmental

Engineering

19-21 April 2016

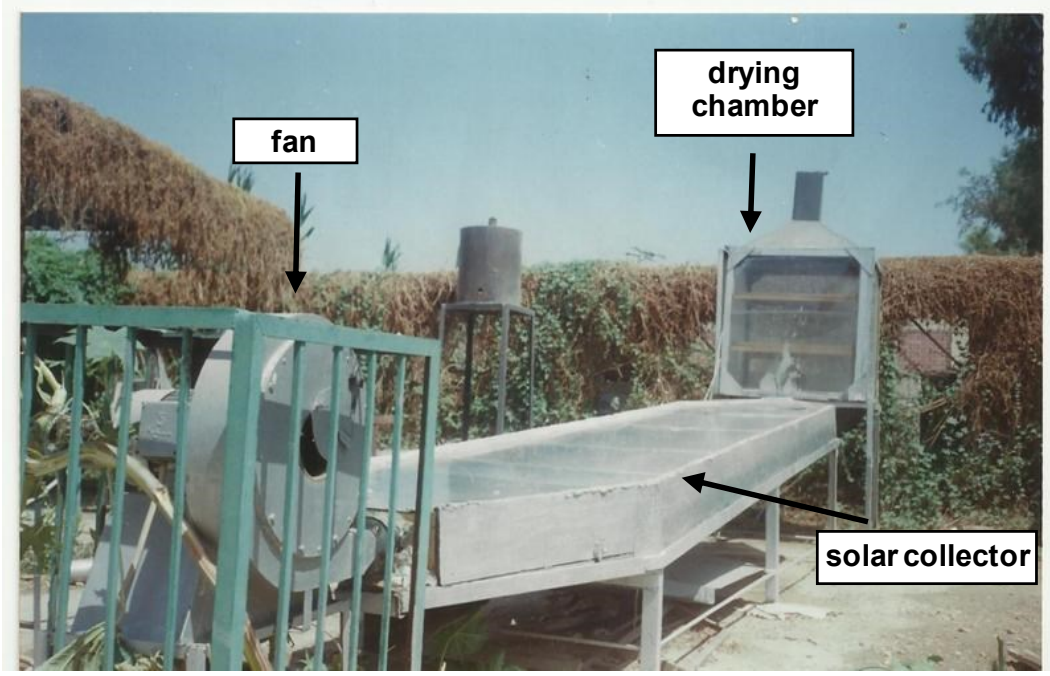

Fig.2. Solar drying assisted system

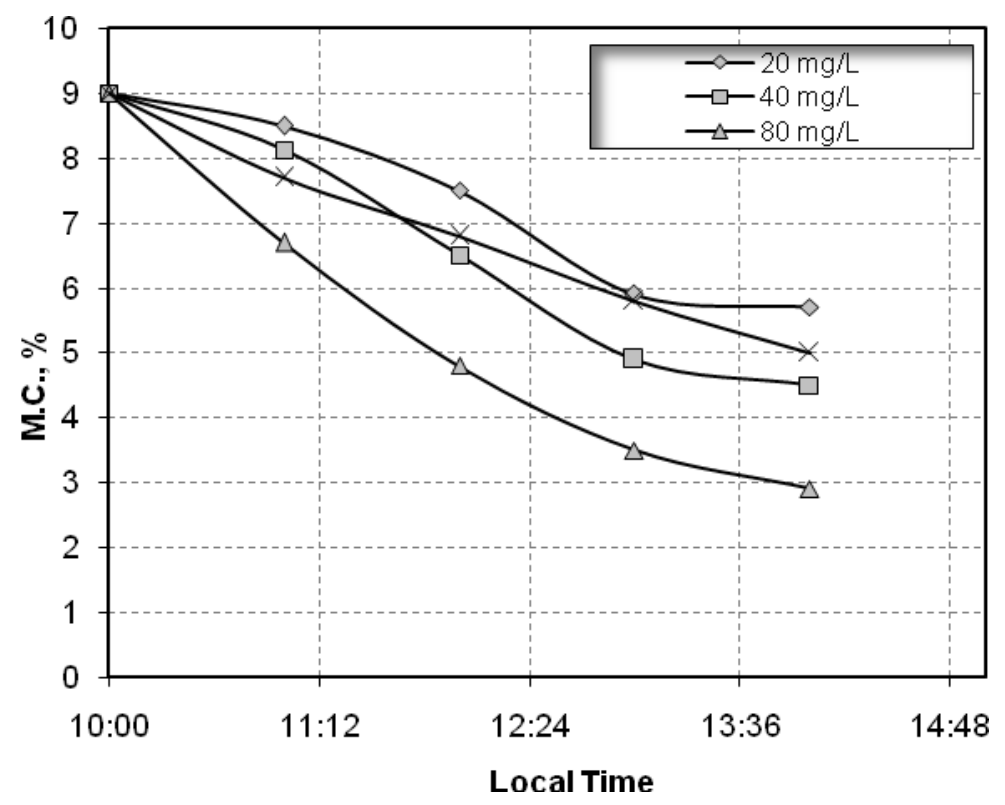

Fig. 3. Effect of traditional $\mathrm{FeCl}_{3}$ conditioner for dewatering 
Military Technical College Kobry El-Kobbah,

Cairo, Egypt

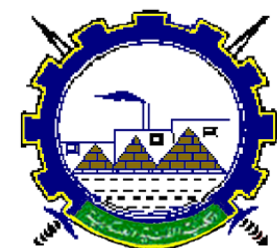

I.C.E.E.2016 $8^{\text {th }}$ International Conference

on

Chemical \& Environmental

Engineering

$19-21$ April 2016

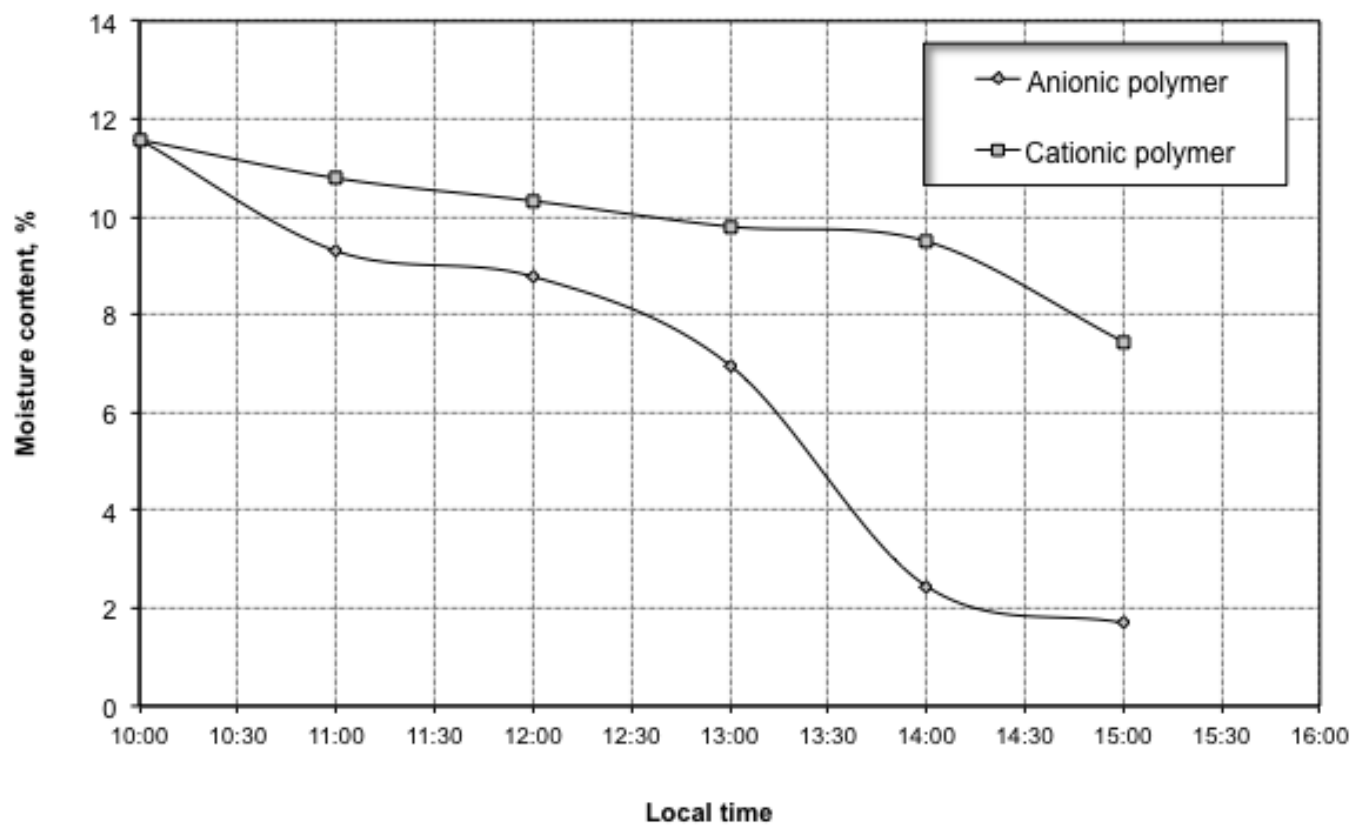

Fig. 4 Effect of polymer addition on the dewaterability

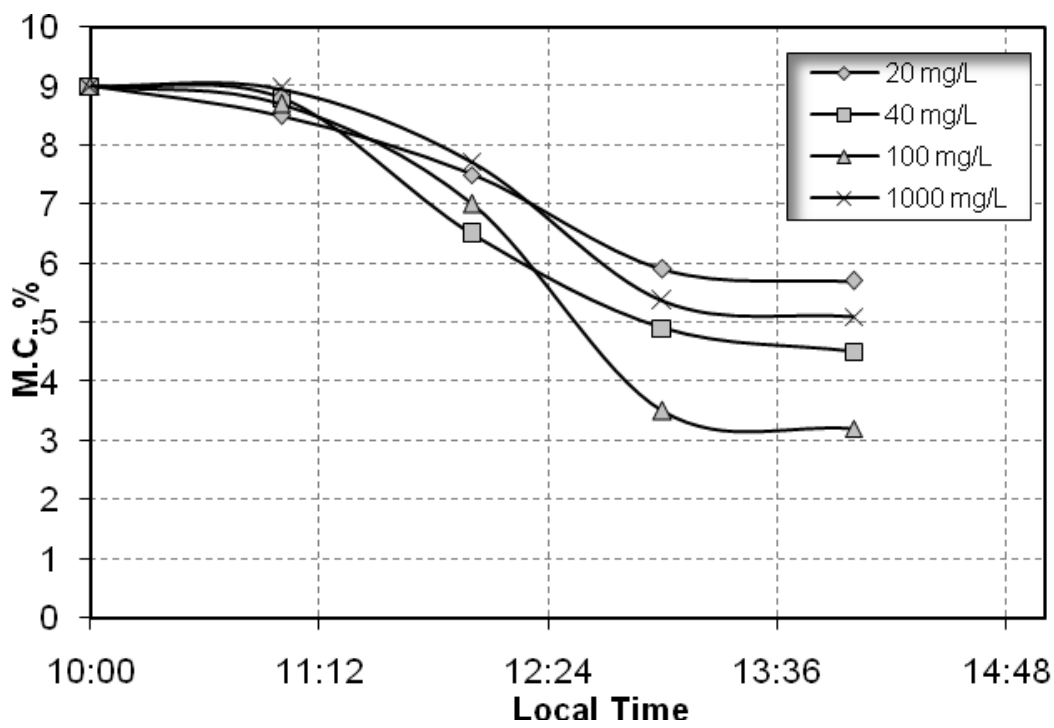

Fig. 5 Effect of Hydrogen Peroxide addition on the dewaterability 
Military Technical College Kobry El-Kobbah,

Cairo, Egypt

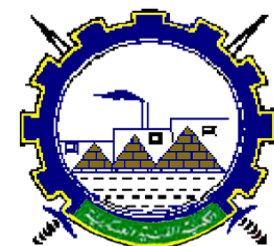

I.C.E.E.2016 $8^{\text {th }}$ International Conference

on

Chemical \& Environmental

Engineering

$19-21$ April 2016

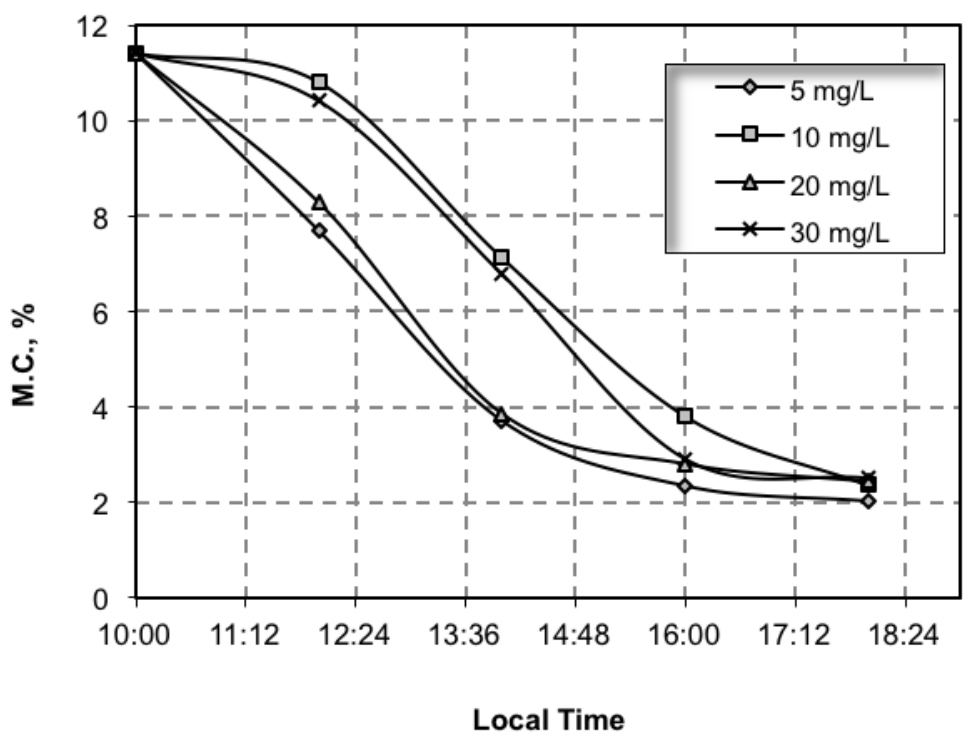

Fig.6 Effect of gypsum dewatering on solar drying
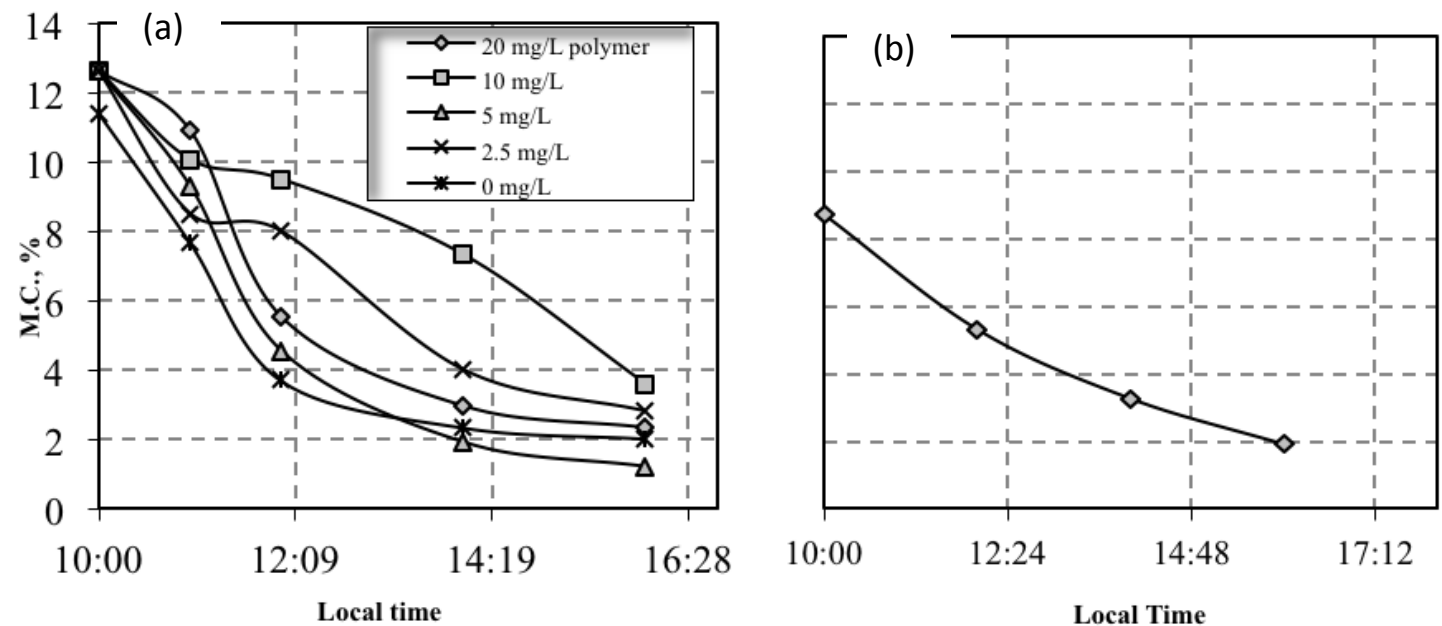

Fig.7 (a) Effect of gypsum-polymer; (b) Effect of gypsum-Fenton dewatering on solar drying 
Military Technical College

Kobry El-Kobbah,

Cairo, Egypt

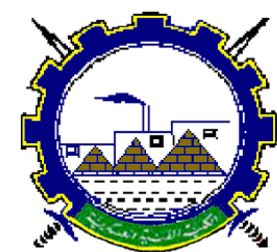

I.C.E.E.2016 $8^{\text {th }}$ International Conference

on

Chemical \& Environmental

Engineering

19-21 April 2016

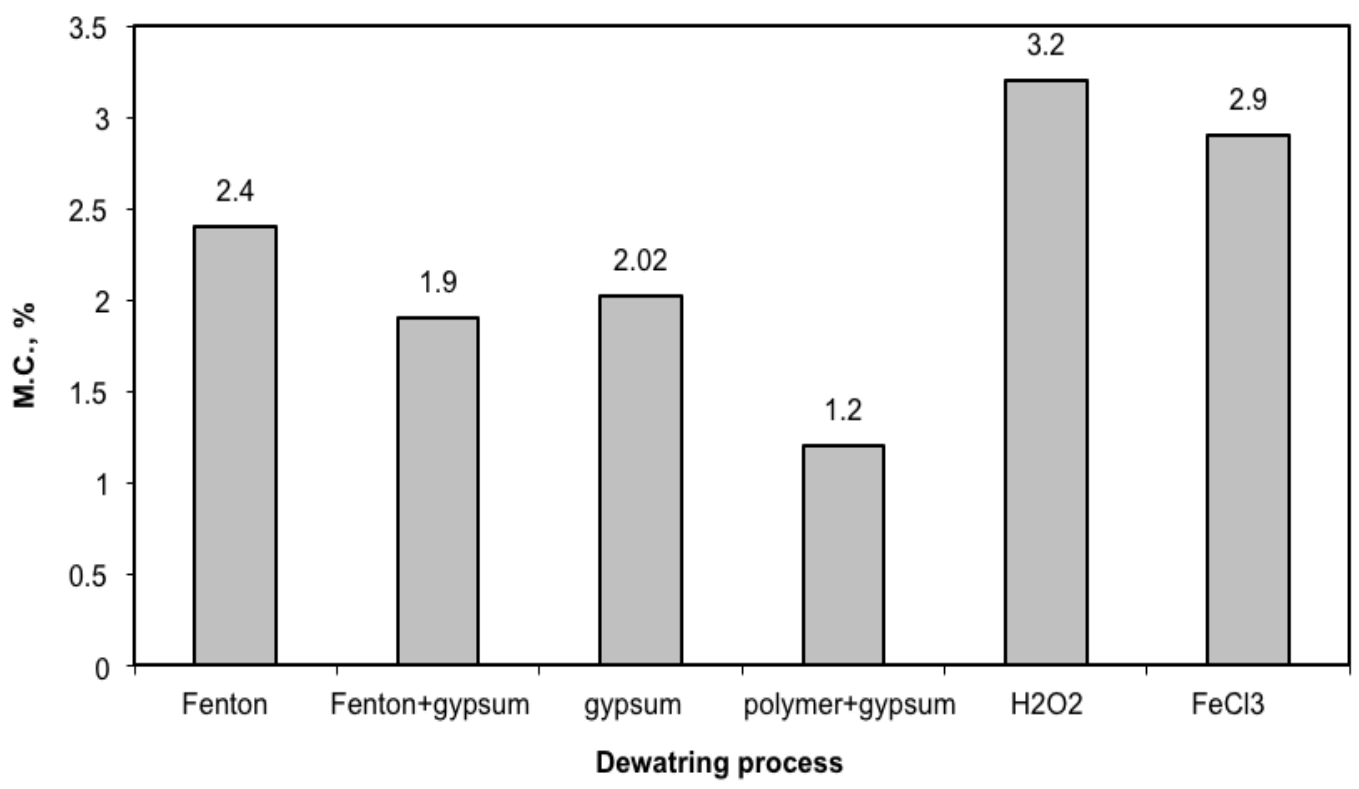

Fig. 8 M.C. reduction (\%) for different dewatering processes on alum sludge 